\title{
A critical review of mathematical models and data used in diabetology
}

\author{
A Boutayeb* ${ }^{* \dagger}$ and A Chetouani ${ }^{\dagger}$
}

\author{
Address: Department of Mathematics Faculty of Sciences, Oujda, Morocco \\ Email: A Boutayeb* - x.boutayeb@menara.ma; A Chetouani - abd.chetouani@menara.ma \\ * Corresponding author †Equal contributors
}

\author{
Published: 29 June 2006 \\ Received: 08 May 2006 \\ BioMedical Engineering OnLine 2006, 5:43 doi:10.1 186//475-925X-5-43 \\ Accepted: 29 June 2006 \\ This article is available from: http://www.biomedical-engineering-online.com/content/5///43 \\ (C) 2006 Boutayeb and Chetouani; licensee BioMed Central Ltd. \\ This is an Open Access article distributed under the terms of the Creative Commons Attribution License (http://creativecommons.org/licenses/by/2.0), \\ which permits unrestricted use, distribution, and reproduction in any medium, provided the original work is properly cited.
}

\begin{abstract}
The literature dealing with mathematical modelling for diabetes is abundant. During the last decades, a variety of models have been devoted to different aspects of diabetes, including glucose and insulin dynamics, management and complications prevention, cost and cost-effectiveness of strategies and epidemiology of diabetes in general. Several reviews are published regularly on mathematical models used for specific aspects of diabetes. In the present paper we propose a global overview of mathematical models dealing with many aspects of diabetes and using various tools. The review includes, side by side, models which are simple and/or comprehensive; deterministic and/or stochastic; continuous and/or discrete; using ordinary differential equations, partial differential equations, optimal control theory, integral equations, matrix analysis and computer algorithms.
\end{abstract}

\section{Introduction}

It is now commonly admitted that diabetes is sweeping the globe as a silent epidemic largely contributing to the growing burden of non-communicable diseases and mainly encouraged by decreasing levels of activity and increasing prevalence of obesity [1-5]. Dramatic increase has occurred in both prevalence and incidence of diabetes, especially with the new threshold proposed by the Expert Committee on the diagnosis and classification of diabetes mellitus in 1997 [6] and adopted by the World Health Organization. During the last decades, a huge number of papers were published on different aspects of diabetes and its complications. In particular, an interesting literature has been devoted to studies collecting, analyzing and validating data concerning diabetes populations. A variety of mathematical models, statistical methods and computer algorithms have been proposed in order to understand different aspects of diabetes such as: glucose-insulin dynamics, epidemiology of diabetes and its complications, cost of diabetes and cost-effectiveness of strategies dealing with diabetes. Several reviews have been devoted to mathematical models and diabetes. In their majority, these reviews concentrated on specific aspects of diabetes such as glucose-insulin dynamics [713], computer algorithms and devices [14-16], sensors and control $[17,18]$, mathematical and software aspects [19], glycemic index [20], burden and cost of diabetes $[21,22]$. On the one side, it is difficult to include in one review mathematical models published on different aspects of diabetes. On the other side, it would be very useful for researchers in this field to get a panorama of the models published so-far and their references. The benefit will be greater if such a review is published with free online access, especially for physicians and researchers in developing countries. The challenge is worth trying and the present paper is proposing a non-exhaustive overview 
including model structure, computer algorithms, data used as input and model validation.

\section{Glucose-insulin dynamics Mathematical models}

The majority of mathematical models proposed in the literature were devoted to the dynamics of glucose-insulin, including Intra Venous Glucose Tolerance Test (IVGTT), Oral Glucose Test (OGTT), Frequently Sampled Intravenous Glucose Tolerance Test (FSIGT). In 1939, Himsworth and Ker [23] introduced the first approach to measure the insulin sensitivity in vivo. Mathematical models have been used to estimate the glucose disappearance and insulin-glucose dynamics in general. Bolie is among the pioneers in this field. In 1961, using ordinary differential equations, he proposed the following simple model [24]:

$$
\begin{aligned}
& \frac{d G}{d t}=-a_{1} G-a_{2} I+p, \\
& \frac{d I}{d t}=-a_{3} G-a_{4} I
\end{aligned}
$$

where $G=G(t)$ represents the glucose concentration, $I=$ $I(t)$ represents the insulin and $p, a_{1}, a_{2}, a_{3}, a_{4}$ are parameters.

Although various models (simple and comprehensive) were proposed by different authors [25-28] (see also the 244 references in the review by Bergman et al. (1985)) [7], especially those dealing with insulin sensitivity, the real start of modeling the glucose-insulin dynamics is thought to begin with the so-called minimal model proposed by the team of Bergman and Cobelli in the early eighties $[29,30]$. The model was formulated as follows:

$$
\begin{aligned}
& \frac{d G(t)}{d t}=-\left[p_{1}+X(t)\right] G(t)+p_{1} G_{b}, G(0)=p_{0} \\
& \frac{d X(t)}{d t}=-p_{2} X(t)+p_{3}\left(I(t)-I_{b}\right), X(0)=0 \\
& \frac{d I(t)}{d t}=p_{4}\left(G(t)-p_{5}\right)^{+} t-p_{6}\left(I(t)-I_{b}\right), I(0)=p_{7}+I_{b}
\end{aligned}
$$

where, $\left(G(t)-p_{5}\right)^{+}=G(t)-p_{5}$ if $G(t)>p_{5}$ and 0 otherwise.

$X(t)$ denotes an auxiliary function representing insulinexcitable tissue glucose uptake activity, $G_{b}$ and $I_{b}$ are the subject's baseline glyceamia and insulinimia. $b_{0}-b_{7}$ are parameters. It should be stressed that, although equations (3)-(5) were developed for describing FSIGT data, these equations were presented into two parts. Part 1 with equa- tions (3)-(4) and part 2 using equation (5). A large number of papers have been published, using modified versions of the glucose minimal model (3)-(4) for describing OGTT and meal tests, while insulin minimal models derived from (5) are still limited to IVGTT. It should also be stated that the major contribution of the glucose minimal model (3)-(4) has been to provide means of estimating insulin sensitivity $S_{I}=p 3 / p 2$, avoiding the glucose clamp.

The same authors have further published papers, completing, testing or validating the results of the minimal model [7,31-33]. An indication of the importance of the minimal model and subsequent research for diabetes understanding is given by the 2006 Banting medal awarded by the American Diabetes Association to Professor Bergman for his achievements.

Variant versions based on the minimal model were considered by different authors. An example of this category was proposed by Derouich and Boutayeb who used a modified version of the minimal model to introduce parameters related to physical exercise [34]:

$\frac{d G(t)}{d t}=-\left(1+q_{2}\right) X(t) G(t)+\left(p_{1}+q_{1}\right)\left(G_{b}-G(t)\right)$,

$\frac{d X(t)}{d t}=-p_{2} X(t)+\left(p_{3}+q_{3}\right)\left(I(t)-I_{b}\right)$,

where $q_{1}, q_{2}, q_{3}$ are parameters related to physical activity and defined as follows:

$q_{1}$ : the effect of physical exercise in accelerating the utilization of glucose by muscles and the liver insulin

$q_{2}$ : the effect of physical exercise in increasing the muscular and liver sensibility to the action of insulin.

$q_{3}$ : the effect of physical exercise in increasing the utilization of insulin. In other words, $q_{3}$ increases insulin effectiveness in enhancing glucose disposal and consequently improving insulin sensitivity to become: $S_{I}=\left(p_{3}+q_{3}\right)(1+$ $\left.p_{2}\right) / P_{2}$.

According to a paper published by Bergman in 2002 [35], more than 500 studies related to the minimal model can be found in the literature. More information on this historic model and related models can be found in literature $[8,9]$.

However, some authors $[19,36-38]$ indicated that while the minimal model has minimal number of constants $\left(p_{0^{-}}\right.$ $p_{7}$ ), and has been indisputably useful in physiological research, it has the following drawbacks: 
1. The model, as originally proposed, is to be regarded as composed of two separate parts. The first part uses equations (3) and (4) and the second part uses equation (5). For the last part, plasma glucose concentration is to be regarded as a known forcing function. In other words, the model parameter fitting has to be conducted in two steps: first, using the recorded insulin concentration as input data in order to derive the parameters in the two first equations, then using the recorded glucose as input data to derive the parameters in the third equation.

2. Some of the mathematical results produced by this model are not realistic(problems of positive equilibrium and solutions not bounded).

3. The artificial non-observable variable $X(t)$ is introduced to take account of the delay in the action of insulin.

Taking into account these remarks and stressing that the glucose-insulin system is an integrated physiologic dynamical system which should be dealt with as a whole, De Gaetano and Arino [36,37] proposed an aggregated delay differential model called a dynamical model:

After renaming the parameters, the dynamical model takes the form [36]:

$\frac{d G(t)}{d t}=-b_{1} G(t)-b_{4} I(t) G(t)+b_{7}, G(0)=G_{b}+b_{0}$

$\frac{d I(t)}{d t}=-b_{2} I(t)+\frac{b_{6}}{b_{5}} \int_{t-b_{5}}^{t} G(s) d s, I(0)=I_{b}+b_{3} b_{0}$

with $G(t)=G_{b}$ for $-b_{5} \leq t<0$

Mukhopadhyay et al. (2004) recalled that this model has been shown to allow simultaneous estimation of both insulin secretion and glucose uptake parameters, to have positive, bounded solutions, and to be globally asymptotically stable around the pre-injection equilibrium blood glucose and insulin concentrations. They proposed an extension by introducing a generic weight function $\omega$ in the delay integral kernel for the pancreatic response to glucose. The new model obtained is as follows:

$$
\begin{aligned}
& \frac{d G(t)}{d t}=-b_{1} G(t)-b_{4} I(t) G(t)+b_{7}, G(0)=G_{b}+b_{0} \\
& \frac{d I(t)}{d t}=-b_{2} I(t)+b_{6} \int_{0}^{\infty} w(s) G(t-s) d s, I(0)=I_{b}+b_{3} b_{0} \\
& \text { with } G(t)=G_{b} \text { for } t<0
\end{aligned}
$$

A more general model was proposed by Li et al. (2001). The authors noted that, while the dynamical model solves the problems of the minimal model, it implicitly or explicitly made a few assumptions that may not be necessary or realistic. Specifically, some of the interaction terms are too special and thus too restrictive. For example, the term $b_{4} I(t) G(t)$ assumes that mass action law applies here while a more popular, general and realistic alternative is to replace this term by $b_{4} I(t) G(t) /(\alpha G(t)+1)$. The way the delay is introduced is also restrictive. Consequently, the model proposed is the following:

$\frac{d X(t)}{d t}=-f(G(t))-g(G(t), I(t))+b_{7}, G(0)=G_{b}+b_{0}$

$\frac{d I(t)}{d t}=-p(I(t))+q\left(L\left(G_{t}\right)\right), I(0)=I_{b}+b_{3} b_{0}$

with $G(t)=G_{b}$ for $-b_{5} \leq t<0$ and $G_{t}(\theta)=G(t+\theta), t>0,-b_{5}$ $\leq \theta<0$.

Other models of the glucose-insulin dynamics, using optimal control or partial differential equations were proposed by different authors [18,40-44]. Cobelli and Tomaseth [41] discussed the optimal input design in a model of glucose kinetics. They proposed the following model:

$$
\begin{aligned}
& \frac{d x(t)}{d t}=A(p) x(t)+B u(t) \\
& y(t)=c(p) x(t) \\
& z(t)=\gamma(t)+e(t) \\
& h[x(t), u(t), p] \geq 0
\end{aligned}
$$

Lam et al. [44] used a slightly modified version of the minimal model for the assessment of insulin sensitivity. An interesting survey of mathematical models using control for glucose-insulin and management of diabetes is given by Palerm in his Ph. D thesis, with some 350 references [18]. The author focussed on the Direct Model Reference Adaptive Control (DMRAC) and its reformulation.

The formulation of the general DMRAC algorithm is based on the following system

$\left\{\begin{array}{c}\frac{d x}{d t}=A x(t)+B u(t) \\ y(t)=C x(t)\end{array}\right.$

or more generally,

$$
\left\{\begin{array}{c}
\frac{d x}{d t}=A x(t)+B u(t) \\
y(t)=C x(t)+D u(t)
\end{array}\right.
$$


where $x(t)$ is the $(n x 1)$ state vector, $u(t)$ is the $(m x 1)$ control vector, $y(t)$ is the $(q x 1)$ output vector, $A, B, C$ and $D$ are matrices with appropriate dimensions. The objective is to find, without explicit knowledge of $A$ and $B$, a control $u(t)$ such that the output vector $y(t)$ fellows a reference model.

\section{Computer algorithms}

The regulation of blood glucose concentration is mainly achieved by acting on three control variables: insulin, meals and physical exercise. However, as stressed by Bellazzi et al. [15], the quantitative evaluation of meals and physical effort still represents a major problem in home monitoring. Consequently, the quasi totality of proposed control systems have focused on insulin therapy strategies. A number of devices-microsystems and computer approaches- have been reported in the literature with open, closed and partially closed algorithms, Selam and Charles [45], Lehman and Deutsch [46,47]. Two reviews on the intravenous route to blood glucose control and subcutaneous route to insulin dependent diabetes therapy were recently published by Bellazzi et al. [15] and Parker et al. [16]. A partial list of software packages, commercially and freely available is given in a recent review by Makroglou et al. [19].

\section{The closed-loop strategy}

An example of models with closed-loop strategy is a wearable artificial pancreas as proposed by Shimoda et al. $[18,48]$, based on the assumption that the relationship between plasma insulin and blood glucose concentration in a normal subject during an oral glucose bolus is as follows:

$$
I(t)=a G(t)+b \frac{d G(t)}{d t}+c
$$

where I denotes the plasma insulin concentration; $G$ is the blood glucose concentration; and $a, b$ and $c$ are parameters that can be estimated by nonlinear least squares method [49].

The insulin dynamics is described by the following ordinary differential system:

$$
\begin{aligned}
& \frac{d X(t)}{d t}=\operatorname{IIR}(t)-I X(t) \\
& \frac{d Y(t)}{d t}=I X(t)-(p+o) Y(t) \\
& \frac{d Z(t)}{d t}=p Y(t)-n Z(t)
\end{aligned}
$$

$$
I(t)=\frac{Z(t)}{V}
$$

where $V$ is the plasma volume, IIR represents the Insulin Infusion Rate; $X, Y$ and $Z$ are the insulin masses in the two subcutaneous compartments and in plasma respectively.

\section{The open-loop approach}

According to the review by Bergman et al. [7], two distinct classes of methodologies were applied to open the glucose/insulin feedback relationship in vivo. The first method pioneered by Reaven and his colleagues [50], and labelled as the pancreatic or insulin suppression test, utilized pharmacologic means to render the pancreas blind to plasma glucose concentration. The second approach, labelled as the glucose clamp, was proposed by Andres [51]. The method uses a variable glucose infusion to establish a relatively constant plasma glucose concentration with or without exogenous insulin. Mathematical models are also proposed to deal with the deterioration of beta-cell [52-54].

\section{Epidemiological models applied to diabetes}

Historically, since the first model of smallpox formulated by Bernoulli in 1760, an abundant literature was devoted to mathematical models dealing with communicable diseases such as measles, rubella, malaria, influenza, AIDS, dengue and others [56]. As indicated by a review published by Hethcote in 2000 [57], a tremendous variety of models have been formulated, mathematically analyzed, and applied to infectious diseases. Modelling has thus become an interesting tool providing conceptual results such as thresholds, basic reproduction numbers, contact numbers, and replacement numbers. Application of similar models for non communicable diseases is rather unusual. In this way, few authors have proposed epidemiological models for diabetes and obesity [58-66]. In [59], Boutayeb and Derouich considered two discrete models for the evolution from diabetes without complications to the stage of diabetes with complications.

In [60], using partial differential equations, the authors proposed an age structured continuous model for complications of diabetes. Supposing that $C=C(a, t)$ and $D=$ $D(a, t)$ represent the numbers of diabetics with and without complications aged $a$ at time $t$, respectively, and $n(a$, $t)=C(a, t)+D(a, t)$ the size of the population of diabetics aged $a$ at time $t$, different scenarios with different values were used for the following parameters: natural death rate $(d(a, t))$, death rate due to complications $(\delta(a, t))$, incidence of diabetes with and without complications $\left(I_{1}(a\right.$, $t)),\left(I_{2}(a, t)\right)$ rate at which complications are developed $(p(a, t))$ and rate at which complications could eventually be cured $(q(a, t))$. The main objective of the authors was 
to show that, although diabetes is not curable at the moment, prevention of its complications (which is possible) would improve peoples quality of life and reduce costs of the national health and social services. Assuming that the number of males is equal to the number of females and that diabetes affects the people of the two sexes equally, the continuous age structured model is formalized by the following partial differential equations:

$$
\begin{aligned}
& \frac{\partial D}{\partial t}+\frac{\partial D}{\partial a}=-d D-p s D+q e C+I_{1} \\
& \frac{\partial C}{\partial t}+\frac{\partial C}{\partial a}=-d^{\prime} C+p s D-q e C+I_{2}
\end{aligned}
$$

adding equations (25) and (26) and writing :

$C(a, t)=r(a, t) n(a, t)$

leads to

$\frac{\partial r}{\partial t}+\frac{\partial r}{\partial t}=\delta r^{2}-\varepsilon r+\omega$

In the same spirit, Boutayeb and colleagues [62,63] proposed linear and non-linear population models of diabetes mellitus, using ordinary differential equations and numerical implementation.

\section{Data analysis, parameters estimation and validation Studies and trials}

Worldwide, different studies were devoted to diabetes and its complications. These studies have been used directly or indirectly for data analysis, mathematical modeling and parameters validation. Among the most cited studies, Diabetes Control Complications Trial (DCCT) [67] and UK Diabetes Prevention Study (UKPDS) [68]. The first trial involved 1,441 volunteers with type 1 diabetes and 29 medical centers in the United States and Canada, and have shown that, diabetes complications can be reduced or at least delayed by a good regular glycemic control through intensive insulin therapy consisting of three or more insulin injections per day or in the use of insulin pumps. The main DCCT Study Findings were the following: Lowering blood glucose reduces the risks of eye disease, kidney failure and nerve disease by $76 \%, 50 \%$ and $60 \%$ respectively [69-72]. The second trial concerned over 5000 non insulin-dependent patients from 23 centres from all parts of England, Scotland and Northern Irland, showing that complications of diabetes can be prevented by a better control of blood glucose and blood pressure. Among the 70 papers published by the UKPDS group, we cite here some of those using mathematical models. The UKPDS risk engine was used as a model for the risk of cor- onary heart disease, myocardial infarctus and stroke in Type II diabetes [73-75]. Modeling glucose exposure as a risk factor for photocoagulation in Type II diabetes was considered in [76], whereas the UKPDS Outcomes Model was proposed to estimate the lifetime health outcomes of patients with Type 2 [77]. Data collection, parameters estimation and validation concerned a multitude of other studies such as: the Wisconsin epidemiologic study of diabetic retinopathy (WESDR) [78], Framingham Heart Study (FHS) [79], Diabetes Prevention Program (DPP) [80], Health Outcomes Prevention Evaluation (HOPE) [81,82], The Health Plan Employer Data and Information Set (HEDIS) [83], Echantillon national temoin représentant des personnes diabétiques (ENTERED) [84], Multiple Risk Factor Intervention Trial (MRFIT) [85], Heart Protection Study (HPS) [86], Cholesterol and Recurrent Events (CARE) [87], ACE Inhibitors and Diabetic Nephropathy Trial (Lewis) [88], the IRMA-2 trial [89], Irbesartan Diabetic Nephropathy Trial (IDNT) [90], the Collaborative AtoRvastatin Diabetes Study (CARDS) [91].

\section{The archimedes model}

According to [92], until recently, there have been four main kinds of mathematical models in health care:

\section{Biological modeling,}

2. Clinical Medicine,

3. Operations research,

\section{Economic/system resources.}

Thus, the authors present Archimedes as a new type of mathematical model which includes all four components. Archimedes is a very detailed, comprehensive, continuous simulation model. A person-by-person, object-by-object simulation, spanning from biological details to the care processes, logistics, resources, and costs of health care systems [92-94]. The model is written in differential equations for which different levels of detail may be considered [95]. The equations, assumptions, and sources are summarised in an online appendix (available at http:/ /care.diabetesjournals.org). A validation of the Archimedes model of diabetes and its complications or a variety of populations, organ systems, treatments, and outcomes is given by Eddy \& Schlessinger [96,97]. The model was validated against 18 trials of which ten trials explicitly dealing with diabetes. Namely: the Diabetes Control and Complications Trial(DCCT) [67], the U.K. Prospective Diabetes Study (UKPDS) [68], the Diabetes Prevention Program (DPP) [80], the Health Outcomes Prevention Evaluation (HOPE) [81], the diabetes subpopulation of the HOPE Trial (Micro-HOPE) [82], the Heart Protection Study (HPS) [86], Cholesterol and 
Recurrent Events (CARE) [87], the ACE Inhibitors and Diabetic Nephropathy Trial (Lewis) [88], the IRMA-2 trial [89], and the Irbesartan Diabetic Nephropathy Trial (IDNT) [90]. In general, between 10 and 30 equations are needed to represent the pathophysiology of the disease and calculate the effect of a specific treatment on a specific outcome in a specific population (not included equations for behaviors, care processes, logistics, and other nonbiological aspects of the model. As stressed by the Editorial of Diabetes Care [98], functional forms of the equation are given but values of the variables and parts of the model that describe micro- and macro-vascular complications are not provided. However, beyond these limitations, the model was used to predict 74 major outcomes, giving astounding results: In 71 out of the 74 clinical outcomes, the differences between the results calculated by the model and the observed ones were statistically not significant. More information on Archimedes model can be found in [92].

\section{Other models}

Other models and computer algorithms were devoted to the burden, cost and cost-effectiveness of diabetes [99101], telemedicine and home management of diabetes [102-104]. In a case study paper [104], Wu proposed the following model for self-management of Type 2 diabetes:

$$
\frac{d^{2} x}{d t^{2}}+\beta \frac{d x}{d t}+\omega_{0}^{2} x=f(t)
$$

where $x$ represents blood glucose level over the baseline at time $t$ and $\omega_{0}$ is the system natural frequency. Finally, in some papers and letters, mathematical models and guidelines for computer modeling of diabetes were subject to debate and criticism [105-107].

\section{Discussion}

Mathematical models constitute interesting tools for the understanding of diseases. They provide insights, improve intuitions, clarify assumptions for formal theory, allow for planning studies, estimating parameters, determining sensitivities, assessing conjectures, simulating simple and complex phenomena and providing future predictions. In the case of diabetes, simple and comprehensive models dealing with different aspects of the disease, have been used during the last three decades. In general, simple models are so simple as to be inadequate but they have the advantage of using a small number of identifiable parameters. Comprehensive models on the other hand are models which try to represent the system (biological, clinical, economic, etc...) by taking into account all interactions. This makes them very complex and generally not identifiable. In the present paper, our main objective was an overview of models and studies dealing with different aspects of diagnosis, care and management of diabetes and its complications. We presented a non exhaustive list of published models with their theoretical and applied aspects, indicating what were the hypotheses that lead authors to propose new, modified, generalized or alternative models. But we must say that we did not intend to compare all models or classify them according to whatever criterion of performance. Even when available models are simple, they are not necessary comparable. For instance, Bolie's model [24] is one of the simplest models proposed to estimate the linear glucose disappearance and insulin-glucose dynamics. However, since the author is one of the pioneers in this field, his work remains an unavoidable reference. Another very simple model was recently proposed in a case study by $\mathrm{Wu}$ [104] but the purpose was a self-management of type 2 diabetes. The model being a case study based on a single type 2 diabetes person, the results yielded need to be considered with caution. The discrete matrix model considered by Boutayeb and Derouich [59] is also simple but the approach is completely different since it deals with the control of complications Bergman et al. [7] discussed seven models before selecting the "best one" which became from then the well known minimal model (between simple inadequate and comprehensive not identifiable models), they based their selection on the following criteria:

\section{1. to be physiologically based,}

2. having parameters that can be estimated with a reasonable precision,

3. parameters with values that are reasonable and have physiological interpretation,

4. best able to simulate the dynamics of the system with smallest number of identifiable parameters.

In section 2, variant versions of the minimal model were considered by different authors. For instance, in Derouich and Boutayeb [34], physical exercise was seen to be an interesting tool that improves insulin sensitivity $\left(S_{I}=\left(p_{3}+\right.\right.$ $\left.\left.\left.q_{3}\right)\left(1+p_{2}\right) / p_{2}\right)\right)$. The authors stressed that new control strategies take a long time before they become affordable on a large scale, especially in developing countries where the majority of diabetics are struggling just to get insulin doses and where the price of a blood strip exceeds the individual income.

As indicated earlier, the minimal model has been indisputably useful in physiological research and served as starting point for many other models. The drawbacks raised by De Gaetano and Arino [36] were mainly based on the mathematical formulation (specifically problems of positive equilibrium and solutions not bounded). But they stressed that no criticism is implied regarding the 
practical usefulness of the minimal model. By the way, they acknowledge that their group uses the minimal model in the routine evaluation of insulin sensitivity in clinical patients. The so-called "dynamic model" proposed by the previous authors has not escaped from criticism since the assumptions made were judged to be not necessary or realistic. This judgement was made by Li et al. [38] who also criticised the restrictive way of using the delay and proposed a more general model. According to these authors, their general model was constructed for the study of IVGTT which focuses on the metabolism of glucose. However, except simulation and mathematical aspects (steady state, oscillatory glucose and insulin levels), no evidence is given on the real performance. For computer algorithms, as stressed earlier, the quasi totality of proposed control systems have focused on insulin therapy strategies. In many cases, the proposition of models are dictated by commercial purposes and the accessibility to their pragmatic use remains restrictive. Finally, among complex comprehensive models, Archimedes model can be seen as the most illustrative. The huge arsenal of computer and mathematical tools used by this model seems to be justified by the first validated results. However, the model has been published recently and more time is needed to get sufficient information for a critical discussion.

\section{Conclusion}

During the last decades, an interesting number of papers have been published on mathematical models and computer algorithms. In the present review, the authors have tried to give a non-exhaustive panorama of the papers which have used mathematical modeling for different aspects of diabetes, including glucose-insulin dynamics, beta-cell function, epidemiology of diabetes, management and the burden of diabetes and its complications.

As indicated in section two, the award of 2006 banting medal by the American Diabetes Association to Professor Bergman for his achievements in diabetes research among which, the famous minimal model, is an indication of the importance of mathematical models for the understanding of diabetes and its management.

\section{Acknowledgements}

The paper is dedicated to the students : Wiam, Sara, Rajae, Oumnia, Mariam, Hanae and Fatima-Zohra for their support to diabetic patients.

The authors are grateful to Prof Wald Editor In Chief of the Biomedical Engineering Online for his comments and suggestions and also for granting a waiver for this publication. The authors wish also to thank anonymous reviewers for their constructive comments and suggestions.

\section{References}

I. The world health report 2003: Today's challenges. [http:// www.who.int/whr/2003/en]. Geneva, World Health Organization
2. International Diabetes Federation: IFD report 2003. [http:// www.idf.org/home/index.cfm].

3. Boutayeb $A$, Boutayeb $S$ : The burden of non communicable diseases in developing countries. Volume 4. International Journal of Equity in Health; 2005:2.

4. Ratner RE: Type $\mathbf{2}$ diabetes mellitus: the grand overview. Diabet Med 1998, 1 4:54-57.

5. Jiwa F: Diabetes in the 1990s -an overview. Stat Bull Metrop Co 1997, 78(I):2-8.

6. The Expert Committee on the Diagnosis and Classification of Diabetes Mellitus: Report of the Expert Committee on the diagnosis and Classification of Diabetes Mellitus. Diabetes Care 1997, 20: II83-II97.

7. Bergman RN, Finegood DT, Ader M: Assessment of Insulin Sensitivity in Vivo. Endicrine Reviews 1985, 6(I):45-86.

8. Bergman RN: The minimal model: yesterday, today and tomorrow. In The minmal model Approach and Determination of Glucose Tolerance Volume 7. Edited by: Bergman RN, Lovejoy JC. Boston : Louisiana state university Press; 1997:3-50.

9. Bergman RN: The minimal model of glucose regulation: a biography. In Mathematical Modeling in Nutrition and Health Edited by: Novotny, Green, Boston. Kluwer Academic/Plenum; 200 I.

10. Nucci G, Cobelli C: Models of subcatuneous insulin kinetics: a critical review. Computer Methods and Programs in Biomedicine 2000, 62:249-257.

II. Sundell J, Knuuti J: Insulin and myocardial blood flow. Cardiovascular Research 2003, 57(2):312-319.

12. Finegood DT: Application of the minimal model of glucose kinetics. In The minmal model Approach and Determination of Glucose Tolerance Volume 7. Edited by: Bergman RN, Lovejoy JC. Boston : Louisiana state university Press; 1997:5I-122.

13. Mari A: Mathematical modelling in glucose metabolism and insulin secretion. Current Opinion Clinical Nutrition Metabolism Care 2002, 5:495-50I.

14. Lehmann ED, Deutsch T: Application of computers in diabetes care: a review. II, Computers for decision support and education. Med Inform 1995, 20:303-329.

15. Bellazzi R, Nucci G, Cobelli C: The Subcutaneous Route to Insulin Dependent Diabetes Therapy: Closed-Loop and Partially Closed-Loop Control Strategies for insulin Delivery and Measuring Glucose Concentration. IEEE Engrg Medicine Biol 200I, 20(I):54-64.

16. Parker RS, Doylelll FJ, Peppas NA: The Intraveneous Route to Blood Glucose Control: A Review of Control Algorithms for Noninvasive Monitoring and Regulation in Type I Diabetic Patients. IEEE Engineering in Medicine and Biologie 200I, 20(1):65-73.

17. Koschinsky T, Heinemann : Sensors for glucose monitoring: technical and clinical aspects. Diabetes/Metabolism Research and Reviews 2001, I7:113-123.

18. Palerm CCR: Drug Infusion Control: An Extended Direct Model Reference Adaptive Control Strategy. In Ph.D Thesis Volume chap 3-4. Rensselear Polytechnic Institute, Troy, New York; 2003:45-60.

19. Makroglou A, Li J, Kuang Y: Mathematical models and software tools for the glucose-insulin regulatory system and diabetes: an overview. Applied Numerical Mathematics 2006, 56:559-573.

20. Kalergis M, De Grandpre E, Andersons C: The Role of the Glycemic Index in the Prevention and Management of Diabetes: A Review and Discussion. Canadian Journal of Diabetes 2005, 29(I):27-38.

21. Atun R, Gurol-Urganci I: Health expenditure: an 'investment' rather than a cost ? International Economics Programme; 2005. IEP XP 05/0I.

22. Boutayeb $A$ : The double burden of communicable and non communicable diseases in developing countries: A review. Transactions of the Royal Society of Tropical Medicine and Hygiene 2006, 100:191-199.

23. Himsworth HP, Ker RB: Insulin-sensitive and insulin insensitive types of diabetes millitus. Cli Sci 1939, 4: I 19-122.

24. Bolie VW: Coefficients of normal blood glucose regulation. J Appl Physiol 196I, 16:783-788.

25. Ackerman E, Gatewood LC, Rosevear JW, Molnar GD: Model studies of blood glucose regulation. Bull Math Biophys 1965, 27:2 I-24.

26. Della C, Romano MR, Voehhelin MR, Seriam E: On a mathematical model for the analysis of the glucose tolerance curve. Diabetes 1970, 19:145-148. 
27. Serge G, TurcogI M, Varcellone G: Modelling blood glucose and insulin kinetics in normal diabetic and obese subjects. Diabetes 1973, 22:94-97.

28. Srinivasan R, Kadish AH, Sridhar R: A mathematical model for the control mechanism of free-fatty acid and glucose metabolism in normal humans. Comp Biomed Res 1970, 3:146- I 49.

29. Bergman RN, Ider YZ, Bowden CR, Cobelli C: Quantitative Estimation of Insulin Sensitivity. Am J Physiol I 979, 23(6):E667-E677.

30. Toffolo G, Bergman RN, Finegood DT, Bowden CR, Cobelli C Quantitaive Estimation of beta cell sensitivity to glucose in the intact organism: a Minimal Model of Insulin kinetics in the Dog. Diabetes 1980, 29:979-990.

31. Bergman RN, Bowden CR, Cobelli C: The Minimal Model approach to quantification of factors controlling glucose disposal in man. In Carbohydrate Metabolism Volume chap 13. Edited by: Cobelli, Bergman. John Wiley \& Sons Ltd; 1981:269-293.

32. Cobelli C, Mari A: Validation of mathematical models complex endocrine-metabomism systems. A case study on a model of glucose regulation. Med \& Biot Eng \& Comput 1983, 21:390-399.

33. Cobelli C, Nucci G, del Prato S: A physiological simulation model of the glucose-insulin system in type I diabetes. Diabetes, Nutrition \& Metabolism 1998, I I ( I):78-80.

34. Derouich $M$, Boutayeb $A$ : The effect of physical exercise on the dynamics of glucose and insulin. Journal of Biomechanics 2002, 35:911-917.

35. Bergman RN: Pathogenesis and prediction of diabetes mellitus: lessons from integrative physiology. Mount Sinai J Medicine 2002, 60:280-290.

36. De Gaetano A, Arino O: Mathematical Modelling of the Intravenous Glucose Tolerance Test. J Math Biol 2000, 40: I36- I68.

37. De Gaetano A, Arino O: A statistical approach to the determination of stability for dynamical systems modelling physiological processes. Math Comput Modelling 2000, 31:4I-5I.

38. Li J, Kuang Y, Li B: Analysis of IVGTT Glucose-Insulin Interaction Models with time delay. Discrete and Continous Dynamical Systems Series B 2000, I(I): 103-124.

39. Mukhopadhyay A, De Gaetano A, Arino O: Modelling the intravenous glucose tolerance test: $A$ global study for single-distributed-delay model. Discrete and Continous Dynamical Systems Series B 2004, 4(2):407-4I7.

40. Cobelli $C$, Thomaseth $\mathrm{K}$ : Optimal input design for identification of compartimental models : theory and applications to a model of glucose kinetics. Mathematical Biosciences 1985 77:267-270.

4l. Cobelli $\mathrm{C}$, Thomaseth $\mathrm{K}$ : The minimal model of glucose disappearence : optimal input studies. Math Biosciences 1987, 83: $127-130$

42. Cobelli $\mathrm{C}$, Thomaseth $\mathrm{K}$ : An optimalality of the impulse input for linear system identification. Math Biosciences 1988, 89:127-129.

43. Cobelli $\mathrm{C}$, Thomaseth $\mathrm{K}$ : Optimal equidose inputs and role of measurement error for estimating the parameters of a compartmental model of glucose kinetics from continuous and discrete time optimal examples. Math Biosciences 89: I35-137.

44. Lam ZH, Hwang KS, Lee JY, Chase JG, Walker GC: Active insulin infusion using optimal and derivative weighted control. Medical engineering physics 2002, 24:663-672.

45. Salam J, Charles MA: Devices for insulin administration. Diabetes care 1999, 13:955-979.

46. Lehman ED, Deutsch T: A physiological model of glucose insulin interaction in type I diabetes mellitus. J Biomed Eng 1992 14:235-242.

47. Lehman ED, Deutsch T, Rondsari AV, Carson ER, Sonksen PH: Validation of a metabolic prototype to assist in the treatment of insulin dependent diabetes mellitus. Volume 18. Med Inform London; 1993:83-101.

48. Shimoda S, Nishida K, Sakakida M, Konno $Y$, ishinose $K$, Uehara M, Nowak T, Shichiri M: Closed-loop subcutaneous isulin infusion algorithm with a short acting insulin analog for long-term clinical application of a wearable artificial endocrine pancreas. Frontiers Med Biol Eng 1997, 8:197-2II.

49. Hashiguchi Y, Sakakida M, Nishida K, Uemura T, Kajiwara K, Shichiri M: Development of a miniaturized glucose monitoring system by combining a needle-type glucose sensor with microdialysis sampling method. Long-term subcutaneous tissue glucose monitoring in ambulatory diabetic patients. diabetes care 1994, 17(5):387-396.

50. Reaven GM, Doberne L, Greenfield MS: Comparaison of insulin secretion and in vivo in-sulin action in non-obese and moderately obese individuals with non-insulin dependent diabetes mellitus. Diabetes 1982, 31:382-388.

5I. Andres R, Swerdloff R, Pozefsky T, Coleman D: Manual feedback technique for the control of blood glucose concentration. In Automation in Analytical Chemistry Edited by: Skeggs Jt LT. Mediad Inc, New York; 1966:486-490.

52. Bagust $A$, Beale $S$ : Deteriorating beta-cell function in type 2 diabetes: a long-term model. Q J Med 2003, 96:28I-288.

53. Matthews DR, Hosker JP, Rudenski AS, Naylor BA, Treacher DF, Turner RC: Homeostasis model assessment: insulin resistance and beta cell function from fasting plasma glucose and insulin concentrations in man. Diabetologia 1985, 28:412-419.

54. Levy JC, Matthews DR, Hermans MP: Correct Homeostasis Model Assessment(HOMA) evaluation uses the computer program(letter). Diabetes Care 1998, 20:2191-2192.

55. Bernoulli D: Essai d'une nouvelle analyse de la mortalité causée par la petite vérole et des avantages de I'inoculation pour la prévenir. In mémoire de mathématiques et de physique Edited by: Académie Royale des Sciences. Paris; 1760: I-45.

56. Hethcote HW: A thousand and one epidemic models. In Frontiers in Theoretical Biology Edited by: Levin. 100, Springer-Verlag, Berlin; 1994:504-515. Lecture notes in Biomath

57. Hethcote HW: The Mathematics of Infectious Diseases. SIAM REVIEW 2000, 42(4):599-653.

58. Boutayeb A, Kerfati A: Mathematical models in diabetology modelling. Measurement and Control, C, AMSE 1994, 44:53-63.

59. Boutayeb A, Derouich M: Age structured models for diabetes in East Morocco. Mathematics and Copmuter Simulation 2002, 58:215-229

60. Boutayeb A, Twizell EH: An age structured model for complications of diabetes mellitus in Morocco. Simulation Modelling Practice and Theory 2004, I 2:77-87.

61. Boutayeb A, Chetouani A: Dynamics of a disabled population in Morocco. Biomedical Engineering Online 2003, 2:2

62. Boutayeb A, Twizell EH, Achouyab K, Chetouani A: A mathematical model for the burden of diabetes and its complications. Biomedical Engineering Online 2004, 3:20.

63. Boutayeb A, Chetouani A, Achouyab K, Twizell EH: A non-linear population model of diabetes mellitus. Journal of Applied Mathematics and computing 2006, 21:127-139.

64. James RC, Blanchard JF, Campbell D, Clottey C, Osei W, Syenson LW, Noseworthy TW: A model for non-communicable disease surveillance in Canada: the prairie pilot diabetes surveillance system. Chronic Dis Can 2004, 25(I):7-I2.

65. Paterson KR: Diabetes epidemiology: present and future. Diabet Med 1999, 16(6):446-7.

66. West KM: Epidemiology of diabetes and its macrovascular complications. Diabetes Care 1979, 2(2):63-4.

67. DCCT Research Group: The effect of intensive treatment of diabetes on the development and progression of long-term complications in insulin dependent diabetes mellitus. New England Journal of Medicine 1993, 329:977-986.

68. O'Neill S: The UK Prospective Diabetes Study(UKPDS): Questions \& Answers. [http://www.diabetes.uk]

69. Rohlfing CL, Wiedmeyer HM, Little RR, England JD, Tennill A, Goldstein DE: Defining the relationship between plasma glucose and HbAlc: analysis of glucose profiles and HbAlc in the Diabetes Control and Complications Trial. Diabetes Care 2000, 25:275-278.

70. Diabetes Control and Complications Trials Research Group: The relationship of glycemic expsure $\left(\mathrm{HbA}_{\mathrm{Ic}}\right)$ to the risk of development and progression of retinopathy in the diabetes control complications trial in insulin-dependent diabetes mellitus. Diabetes 1995, 44:968-983.

71. Diabetes Control and Complications Trials Research Group: The absence of a glycemic threshold for the development of longterm complication: the perspective of the diabetes control complications trial in insulin-dependent diabetes mellitus. Diabetes 1996, 45: 1289-1298.

72. Diabetes Control and Complications Trials Research Group: Hypoglycemia in the Diabetes Control Complications Trial. Diabetes 1997, 45:27I-286. 
73. Stevens RJ, Kothari V, Adler AI, Stratton IM, Holman RR, (UKPDS Group): The UKPDS risk engine: a model for the risk of coronary heart disease in Type II diabetes (UKPDS 56). Clinical Science 200I, I0 I:67I-679.

74. Kothari V, Stevens RJ, Adler AI, Stratton IM, Manley SE, Neil HA, Holman RR: Risk of Stroke in type 2 diabetes Estimated by the UKPDS risk engine (UKPDS 60). Stroke 2002, 33:776- I78I.

75. Stevens RJ, Coleman RL, Adler AI, Stratton IM, Matthews DR, Holman RR: Risk Factors for myocardial Infarction Case Fatality and Stroke Case Fatality in Type 2 Diabete (UKPDS 66). Diabetes Care 2003, 27(I):20I-207.

76. Stevens RJ, Stratton IM, Holman RR: Modeling glucose exposure as a risk factor for photocoagulation in type 2 diabetes (UKPDS 58). Journal of Diabetes Complications 2002, I 6(6):37|-376.

77. Clarke PM, Gray AM, Briggs A, Farmer AJ, Fenn P, Stevens RJ, Matthews DR, Stratton IM, Holman RR, (UKPDS Group): A model to estimate the lifetime health outcomes of patients with Type 2 diabetes: The UKPDS Outcomes Model (UKPDS 68). Diabetologia 2004, 47:1747-I759.

78. Klein R, Klein BEK, Moss SE, Davis MD, Demets DL: The Wisconsin epidemiologic study of diabetic retinopathy (WESDR IX): Four year incidence and progression of diabetic retinopathy when age at diagnosis is less than $\mathbf{3 0}$ years. Archives Ophtalmologic 1989, 107:237-243.

79. Framingham Heart Study [http://www.framingham.com/heart]

80. Diabetes Prevention Program Research Group: Reduction in the incidence of type 2 diabetes with lifestyle intervention or metformin. New England Journal of Medicine 2002, 356:393-402.

81. The Health Outcomes Prevention Evaluation Study investigators: Effects of angiotension-converting-enzyme inhibitor, ramipril on cardiovascular events in high-risk patients. New England Journal Medicine 2000, 342: I 45-I 53.

82. The Health Outcomes Prevention Evaluation Study investigators: Effects of ramipril on cardiovascular and microvascular outcomes in people with diabetes mellitus: results of the HOPE study and MICRO HOPE substudy. Lancet 2000, 355:253-259.

83. The Health Plan Employer Data and Information Set (HEDIS) [http://www.ncqa.org/Programs/HEDIS]

84. Echantillon national temoin représentant des personnes diabétiques [http://www.invs.sante.fr/publications/entred/index.html]

85. Multiple Risk Factor Intervention Trial [http://www.gpnote book.co.uk/cache/-I77799/655.htm]

86. Heart Protection Study (HPS) [http://www.hps.com]

87. Cholesterol and Recurrent Events (CARE) [http://
[ www.care.com]

88. Lewis EJ, Hunsicker LG, Clarke WR, Raymond P, Berl T, Rohde R, Raz $\mathrm{I}$ : The effect of angioitensin-converting-enzyme inhibition on diabetic nephropathy antagonist irbesartan in patients with nephropathy due to type $\mathbf{2}$ diabetes. New England Journal of Medicine 1993, 329:|456-|462.

89. Irbesartin in Patients with Type-2 Diabetes and Microalbuminuria Study Group: The effect of Irbesartin on the development of diabetic nephropathy in patients with type 2 diabetes. New England Journal of Medicine 200 I, 345:870-878.

90. Lewis EJ, Hunsicker LG, Clarke WR, Tomas P, Pohl MA, Lewis JB, Ritz E, Alkins RC, Rohde R, Raz I: Renoprotective effect of the angioitensin-receptor antagonist irbesartan in patients with nephropathy due to type 2 diabetes. New England Journal of Medicine 200I, 345:85I-860.

91. Colhoun HM, Thomason MJ, Mackeness MI, Moton SM, Betteridge DJ, Durrington PN, Mitman GA, Neil MA, Fuller JH: Design of the Collaborative AtoRvastatin Diabetes Study in patients with type 2 diabetes (CARDS). Diabetes Medicine 2002, I9(3):20I-2II.

92. American Diabetes Association: Diabetes PHD and Archimedes. [http://www.archimedesmodel.com/pdf/archimedesintro selfguided press.pdf].

93. Brandeau ML: Modeling complex Medical Decision Problems with Archimedes Model. Annals of Internal Medicine 2005, | 43:303-304.

94. Kahn R: Dealing with complexity in clinical diabetes: the value of Archimedes. Diabetes Care 2003, 26(I I):3 I68-3I7I.

95. Schlessinger L, Eddy DM: Archimedes: A new model simulating health care systems: the mathematical formulation. Journal of Biomedical Informatics 2002, 35(I):37-50.
96. Eddy DM, Schlessinger L: Archimedes: A trial-validated model of diabetes. Diabetes Care 2003, 26(I I):3093-3 I0I.

97. Eddy DM, Schlessinger L: Validation of the Archimedes diabetes model. Diabetes Care 2003, 26(II):3 I02-3II0.

98. Herman WH: Diabetes Modeling. Diabetes Care 2003, 26(I I):3 |82-3 |83.

99. Bagust A, Hopkinson PK, Maier W, Currie C): An economic model of the the long-term care burden of type II diabete. Diabetologia 200I, 44:2। 40-2I 55.

100. Eastman RC, Javitt JC, Herman WH, Dasbach EJ, Zbrozek AS, Dong F, Mannienen D, Garfield SA, Copley-Merriman C, Maier W, Eastman JF, Kotsanos J, Cowie CC, Harris M: Model of complications of NIDDM II: Model construction and assumptions. Diabetes Care 1997, 20:725-734.

I0I. Eastman RC, Javitt JC, Herman WH, Dasbach EJ, Copley-Merriman C, Maier W, Dong F, Mannienen D, Zbrozek AS, Kotsanos J, Garfield SA, Harris M: Model of complications of NIDDM. II: Analysis of the health benefits and cost-effectiveness of treating NIDDM with the goal of normoglycaemia. Diabetes Care 1997, 20:735-744.

102. Hernando ME, Garcia A, Perdices FJ, Torralba V, Gomez EJ, del Pozo F: Multi-Agent Architecture for the provision of Intelligent Telemedicine Services in Diabetes Management. [http:// www.gbt.tfo.upm.es]

103. Brown JB, Russel A, Chan W, Pedula K, Aickin M: The global diabetes model: user friendly version 3.0. Diabetes Res Clin Pract 2000, 50(3):SI5-S46.

104. Wu H: A case study of type 2 diabetes self-management. Biomedical Engineering Online 2005, 4:4.

105. American Diabetes Association Consensus panel: Guidelines for Computer Modeling of Diabetes and its Complications. (Consensus Statement). Diabetes Care 2004, 27( I I):2262-2265.

106. Bagust A, McEwan P: Guidelines for Computer Modeling of Diabetes and its Complications. (Response to American Diabetes Association Consensus Panel). Diabetes Care 2005, 28( I I):500.

107. Khan R: Guidelines for Computer Modeling of Diabetes and its Complications.(Response to Bagust and McEwan). Diabetes Care 2005, 28( I I):50I.

Publish with BioMed Central and every scientist can read your work free of charge

"BioMed Central will be the most significant development for disseminating the results of biomedical research in our lifetime. "

Sir Paul Nurse, Cancer Research UK

Your research papers will be:

- available free of charge to the entire biomedical community

- peer reviewed and published immediately upon acceptance

- cited in PubMed and archived on PubMed Central

- yours - you keep the copyright
BioMedcentral 